\title{
Redefining the Positive Circumferential Resection Margin by Incorporating Preoperative Chemoradiotherapy Treatment Response in Locally Advanced Rectal Cancer: A Multicenter Validation Study
}

\author{
Joo Ho Lee, MD ${ }^{1}$ \\ Eui Kyu Chie, MD, PhD' \\ Seung-Yong Jeong, $\mathrm{MD}, \mathrm{PhD}^{2}$ \\ Tae-You Kim, MD, $\mathrm{PhD}^{3}$ \\ Dae Yong Kim, MD, PhD ${ }^{4}$ \\ Tae Hyun Kim, MD, PhD ${ }^{4}$ \\ Sun Young Kim, MD, $\mathrm{PhD}^{4}$ \\ Ji Yeon Baek, MD, PhD ${ }^{4}$ \\ Hee Jin Chang, MD, $P h D^{4}$ \\ Min Ju Kim, MD, PhD ${ }^{4}$ \\ Sung Chan Park, MD, $\mathrm{PhD}^{4}$ \\ Jae Hwan Oh, MD, $\mathrm{PhD}{ }^{4}$ \\ Sung Hwan Kim, MD, PhD ${ }^{5}$ \\ Jong Hoon Lee, MD, PhD \\ Doo Ho Choi, MD, PhD ${ }^{6}$ \\ Hee Chul Park, MD, PhD \\ Sung-Bum Kang, $\mathrm{MD}, \mathrm{PhD}^{7}$ \\ Jae-Sung Kim, MD, PhD ${ }^{8}$
}

*A list author's affiliations appears at the end of the paper.

\section{Purpose}

This study was conducted to validate the prognostic influence of treatment response among patients with positive circumferential resection margin for locally advanced rectal cancer.

\section{Materials and Methods}

Clinical data of 197 patients with positive circumferential resection margin defined as $\leq 2 \mathrm{~mm}$ after preoperative chemoradiotherapy followed by total mesorectal excision between 2004 and 2009 were collected for this multicenter validation study. All patients underwent median 50.4 Gy radiation with concurrent fluoropyrimidine based chemotherapy. Treatment response was dichotomized to good response, including treatment response of grade 2 or 3 , and poor response, including grade 0 or 1.

\section{Results}

After 52 months median follow-up, 5-year overall survival (OS) for good responders and poor responders was $79.1 \%$ and $48.4 \%$, respectively $(p<0.001)$. In multivariate analysis, circumferential resection margin involvement and treatment response were a prognosticator for OS and locoregional recurrence-free survival. In subgroup analysis, good responders with close margin showed significantly better survival outcomes for survival. Good responders with involved margin and poor responders with close margin shared similar results, whereas poor responders with involved margin had worst survival (5-year 0S, 81.2\%, 57.0\%, $50.0 \%$, and $32.4 \%$, respectively; $p<0.001$ ).

\section{Conclusion}

Among patients with positive circumferential resection margin after preoperative chemoradiotherapy, survival of the good responders was significantly better than poor responders. Subgroup analysis revealed that definition of positive circumferential resection margin may be individualized as involvement for good responders, whereas $\leq 2 \mathrm{~mm}$ for poor responders.

\footnotetext{
Correspondence: Eui Kyu Chie, MD, PhD Department of Radiation Oncology, Seoul National University College of Medicine, 101 Daehak-ro, Jongno-gu, Seoul 03080, Korea Tel: 82-2-2072-3705

Fax: 82-2-765-3317

E-mail: ekchie93@snu.ac.kr

Received December 23, 2016 Accepted May 17, 2017

Published Online May 24, 2017
}

\section{Key words}

Rectal neoplasms, Chemoradiotherapy, Neoadjvant therapy, Margins of excision, Treatment response 


\section{Introduction}

Positive circumferential margin (CRM) is known to be one of the strongest prognostic factor in locally advanced rectal cancer $[1,2]$. Although total mesorectal excision (TME) have dramatically decreased the risk of residuum, the prognosis of the patients with positive CRM after standard preoperative chemoradiotherapy (CRT) and TME is still far from satisfactory $[3,4]$.

Although the prognostic impact of CRM is well appreciated [1,2], the definition of positive CRM have been controversial ranging from margin involvement $(0 \mathrm{~mm})$ to $2 \mathrm{~mm}$ 's $[1,3,5,6]$. However, various clinical factors, which would influence both prognosis and treatment decision, were not incorporated in the definition of positive CRM. Moreover, the patients with positive CRM have been considered as a relatively homogenous group having a poor prognosis with very low chance of cure. In the era of the precision oncology, approach to positive CRM should be individualized incorporating various relevant factors and diverse clinical settings [3,4,7-9].

Although, there are studies looking into the prognostic impact of treatment response in rectal cancer [10-12], this impact might be different depending on the risk of residual disease near CRM [10]. For the prognostic impact and definition of positive CRM, the clinical value of the treatment response has not been elucidated in the previous studies.

Authors have previously reported that the clinical impact of positive CRM might be different according to the degree of treatment response after preoperative CRT and long-term survival might be warranted for good responders despite positive CRM [7]. Retrospective multicenter study was launched through Korean Radiation Oncology Group (KROG) to investigate the relationship between the prognostic effect of positive CRM and the treatment response after preoperative CRT.

\section{Materials and Methods}

\section{Hypothesis and sample size}

We hypothesized that the prognostic effect and definition of positive CRM may be different according to treatment response. To validate the hypothesis, statistical power was calculated to detect the prognostic effect of treatment response. Reported overall survival (OS) for clinical stage II or III rectal cancer patients with negative CRM is $80 \%$, whereas that of patients with positive CRM is $60 \%[3,7,8]$.
Thus, survival for good responders was set at $80 \%$, whereas that for poor responders was set at $60 \%$. With detection power at $10 \%$ in one-tailed test with $10 \%$ drop-out rate, calculated sample size was 196 patients. Primary end-point was OS, and secondary end-points were disease-free survival (DFS), locoregional recurrence-free survival and distant metastasis-free survival. This trial was registered at http:// www.KROG.or.kr (protocol number 13-01).

\section{Eligibility}

Eligibility criteria were as follows: before CRT: (1) histologically confirmed rectal adenocarcinoma, (2) cT3-4 or cN12 classification, (3) no distant metastasis, and (4) no prior treatment; CRT: (5) preoperative conventionally fractionated CRT and (6) treatment initiated between January 2004 and December 2009; after CRT: (7) curative TME, (8) CRM $\leq 2 \mathrm{~mm}$. Exclusion criteria were as follows: (1) non-adenocarcinoma histology, (2) distant metastasis detected prior to preoperative treatment, (3) unresected synchronous colon malignancy, (4) CRT to surgery interval longer than 3 months, (5) gross residuum, and (6) local excision for primary lesion. Institutional review board approval was obtained from KROG and at each participating institution. Collected data were transferred to the KROG Data Management Center (National Cancer Center, Goyang, Korea) for analysis.

\section{Evaluation}

The following data were collected from each patient: age, gender, Eastern Cooperative Oncology Group (ECOG) performance status, distance from the anal verge to the caudal tumor edge, pretreatment clinical TNM classification, pretreatment and post-treatment carcinoembryonic antigen (CEA) level, radiotherapy date and dose, chemotherapy regimens and dose, surgery date and method, postoperative pathologic stage, CRM distance, lymphatic/vascular/perineural invasion, pathologic response to preoperative CRT, postoperative adjuvant treatment, date and site of relapse, and status at last follow-up.

Initial clinical staging was based on colonoscopy, computed tomography of abdomen and pelvis, magnetic resonance imaging of pelvis with or without endorectal ultrasonography, and computed tomography of chest. Whole body ${ }^{18} \mathrm{~F}$-fluorodeoxyglucose positron emission tomography was performed per discretion. Pretreatment clinical and postCRT pathologic stages were reviewed on registration and were determined according to the American Joint Committee on Cancer TNM staging system, seventh edition [13].

The pathologic responses were categorized into 4 tiers as reported previously [14]. Grade 0 was defined as no evidence 
Table 1. Patient and treatment characteristics

\begin{tabular}{|c|c|c|c|}
\hline Characteristic & $\begin{array}{l}\left.\text { Good responders }{ }^{\mathrm{a}}\right) \\
\qquad(\mathrm{n}=125)\end{array}$ & $\begin{array}{l}\text { Poor responders }{ }^{b)} \\
\qquad(n=68)\end{array}$ & p-value ${ }^{c}$ \\
\hline Age (yr) & $59(33-83)$ & $59(27-83)$ & \\
\hline \multicolumn{4}{|l|}{ Sex } \\
\hline Male & $79(63.2)$ & $48(70.6)$ & 0.301 \\
\hline Female & $46(36.8)$ & $20(29.4)$ & \\
\hline \multicolumn{4}{|l|}{ ECOG } \\
\hline 0 & $56(44.8)$ & $35(51.5)$ & 0.508 \\
\hline 1 & $67(53.6)$ & $31(45.6)$ & \\
\hline $2-3$ & $2(1.6)$ & $2(2.9)$ & \\
\hline \multicolumn{4}{|l|}{ Clinical T classification } \\
\hline $\mathrm{T} 2$ & $2(1.6)$ & $2(2.9)$ & 0.540 \\
\hline T3 & $110(88.0)$ & $56(82.4)$ & \\
\hline $\mathrm{T} 4$ & $13(10.4)$ & $10(14.7)$ & \\
\hline \multicolumn{4}{|l|}{ Clinical N classification } \\
\hline $\mathrm{N}(-)$ & $28(22.4)$ & $8(11.8)$ & 0.070 \\
\hline $\mathrm{N}(+)$ & $97(77.6)$ & $60(88.2)$ & \\
\hline \multicolumn{4}{|l|}{ Distance from anal verge $(\mathrm{cm})$} \\
\hline$\leq 2$ & $22(17.6)$ & $7(10.3)$ & 0.314 \\
\hline$>2$ and $\leq 7$ & $87(69.6)$ & $49(72.1)$ & \\
\hline$>7$ & $16(12.8)$ & $12(17.6)$ & \\
\hline \multicolumn{4}{|l|}{ Pretreatment CEA } \\
\hline $\operatorname{Normal}(\leq 5 \mathrm{ng} / \mathrm{mL})$ & $71(57.7)$ & $33(49.3)$ & 0.262 \\
\hline Elevated (> $5 \mathrm{ng} / \mathrm{mL})$ & $52(42.3)$ & $34(50.7)$ & \\
\hline Radiation dose (Gy) & $50.4(44-54)$ & $50.4(44-4)$ & \\
\hline \multicolumn{4}{|l|}{ Concurrent chemotherapy regimen } \\
\hline $5-\mathrm{FU}$ & $90(72.0)$ & $47(69.1)$ & 0.207 \\
\hline Capecitabine & $19(15.2)$ & $10(14.7)$ & \\
\hline Tegafur/Uracil & $1(0.8)$ & $4(5.9)$ & \\
\hline Capecitabine/Irinotecan \pm Erbitux & $15(12.0)$ & $7(10.3)$ & \\
\hline \multicolumn{4}{|l|}{ Type of surgery } \\
\hline Sphincter preservation surgery & $89(71.2)$ & $51(75.0)$ & 0.572 \\
\hline Abdominoperineal resection & $36(28.8)$ & $17(25.0)$ & \\
\hline \multicolumn{4}{|l|}{ ypT classification } \\
\hline Tis-T2 & $24(19.2)$ & $2(2.9)$ & 0.003 \\
\hline T3 & $93(74.4)$ & $57(83.8)$ & \\
\hline $\mathrm{T} 4$ & $8(6.4)$ & $9(13.2)$ & \\
\hline \multicolumn{4}{|l|}{ ypN classification } \\
\hline N0 & $71(56.8)$ & $21(30.9)$ & $<0.001$ \\
\hline N1 & $40(32.0)$ & $26(38.2)$ & \\
\hline N2 & $14(11.2)$ & $21(30.9)$ & \\
\hline \multicolumn{4}{|l|}{ ypStage } \\
\hline 0 (is) & $1(0.8)$ & 0 & $<0.001$ \\
\hline I & $20(16.0)$ & $1(1.5)$ & \\
\hline II & $53(42.4)$ & $20(29.4)$ & \\
\hline III & $51(40.8)$ & $47(69.1)$ & \\
\hline \multicolumn{4}{|l|}{ CRM (mm) } \\
\hline 0 & $8(6.4)$ & $24(35.3)$ & $<0.001$ \\
\hline $0.1-1.0$ & $60(48.0)$ & $27(39.7)$ & \\
\hline $1.1-2.0$ & $57(45.6)$ & $17(25.0)$ & \\
\hline
\end{tabular}

(Continued to the next page) 
Table 1. Continued

\begin{tabular}{|c|c|c|c|}
\hline Characteristic & $\begin{array}{l}\left.\text { Good responders }^{a}\right) \\
\qquad(n=125)\end{array}$ & $\begin{array}{l}\text { Poor responders }{ }^{\text {b) }} \\
\qquad(n=68)\end{array}$ & p-value ${ }^{c}$ \\
\hline \multicolumn{4}{|l|}{ Downstaging } \\
\hline Yes & $58(46.4)$ & $19(27.9)$ & 0.009 \\
\hline No & $67(53.6)$ & $49(72.1)$ & \\
\hline \multicolumn{4}{|l|}{ Lymphatic invasion } \\
\hline Yes & $26(20.8)$ & $30(44.1)$ & 0.001 \\
\hline No & $98(78.4)$ & $38(55.9)$ & \\
\hline Not evaluated & $1(0.8)$ & & \\
\hline \multicolumn{4}{|l|}{ Vascular invasion } \\
\hline Yes & $18(14.4)$ & $31(45.6)$ & $<0.001$ \\
\hline No & $103(82.4)$ & $37(54.4)$ & \\
\hline Not evaluated & $4(3.2)$ & & \\
\hline \multicolumn{4}{|l|}{ Perineural invasion } \\
\hline Yes & $40(32.0)$ & $36(52.9)$ & 0.007 \\
\hline No & $81(64.8)$ & $32(47.1)$ & \\
\hline Not evaluated & $4(3.2)$ & & \\
\hline \multicolumn{4}{|l|}{ Adjuvant treatment } \\
\hline Chemotherapy & $113(90.4)$ & $62(91.2)$ & 0.736 \\
\hline Chemoradiotherapy & $4(3.2)$ & $1(1.5)$ & \\
\hline Radiotherapy & $1(0.8)$ & 0 & \\
\hline Observation & $7(5.6)$ & $5(7.4)$ & \\
\hline \multicolumn{4}{|c|}{ Adjuvant chemotherapy/Chemoradiotherapy regimen } \\
\hline $5-\mathrm{FU}$ & $89(71.2)$ & $41(60.3)$ & 0.801 \\
\hline Capecitabine or tegafur/Uracil & $19(15.2)$ & $8(11.8)$ & \\
\hline 5-FU+oxaliplatin/Irinotecan & $9(7.2)$ & $14(20.5)$ & \\
\hline
\end{tabular}

Values are presented as median (range) or number (\%). ECOG, Eastern Cooperative Oncology Group; CEA, carcinoembryonic antigen; 5-FU, 5-fluorouracil; CRM, circumferential resection margin. ${ }^{\text {a) }}$ Treatment response grade 2 or 3 , b) Treatment response grade 0 or $1,{ }^{c}$ Chi-square test.

of radiation-related changes (fibrosis, necrosis, vascular change), no regression. Grade 1 was defined as dominant tumor mass with obvious radiation-related changes, minimal regression. Grade 2 was defined as dominant radiationrelated changes with residual tumor, moderate regression. Grade 3 was defined as microscopic residual tumor in fibrotic tissue, near total regression.

To evaluate the prognostic effect of treatment response in the present study, patients were arbitrarily divided into two subgroups. Good responder was defined as patients with pathologic response of grade 2 or 3 , whereas poor responder was defined as patients with grade 0 or 1 .

\section{Statistical analysis}

OS was defined as the time from the first day of treatment to the date of death from any cause, with survivors being censored at the time of the last follow-up. Similarly, DFS, locoregional recurrence-free survival (LRFS), and distant metastasis-free survival (DMFS) were calculated as the interval from the first day of the treatment to the date of any recurrent disease detection, locoregional relapse detected in pelvic cavity, and distant metastasis detection, or death, whichever occurred first, respectively.

Kaplan-Meier method was used for survival curve, logrank test for univariate survival comparisons, and Cox proportional hazards model backward stepwise selection procedure for multivariate analyses. Chi-square test was used for comparison of parameters between the subgroups. $\mathrm{p}<0.05$ was considered statistically significant. SPSS ver. 19 (SPSS Inc., Chicago, IL) was used for all statistical analyses. 
A
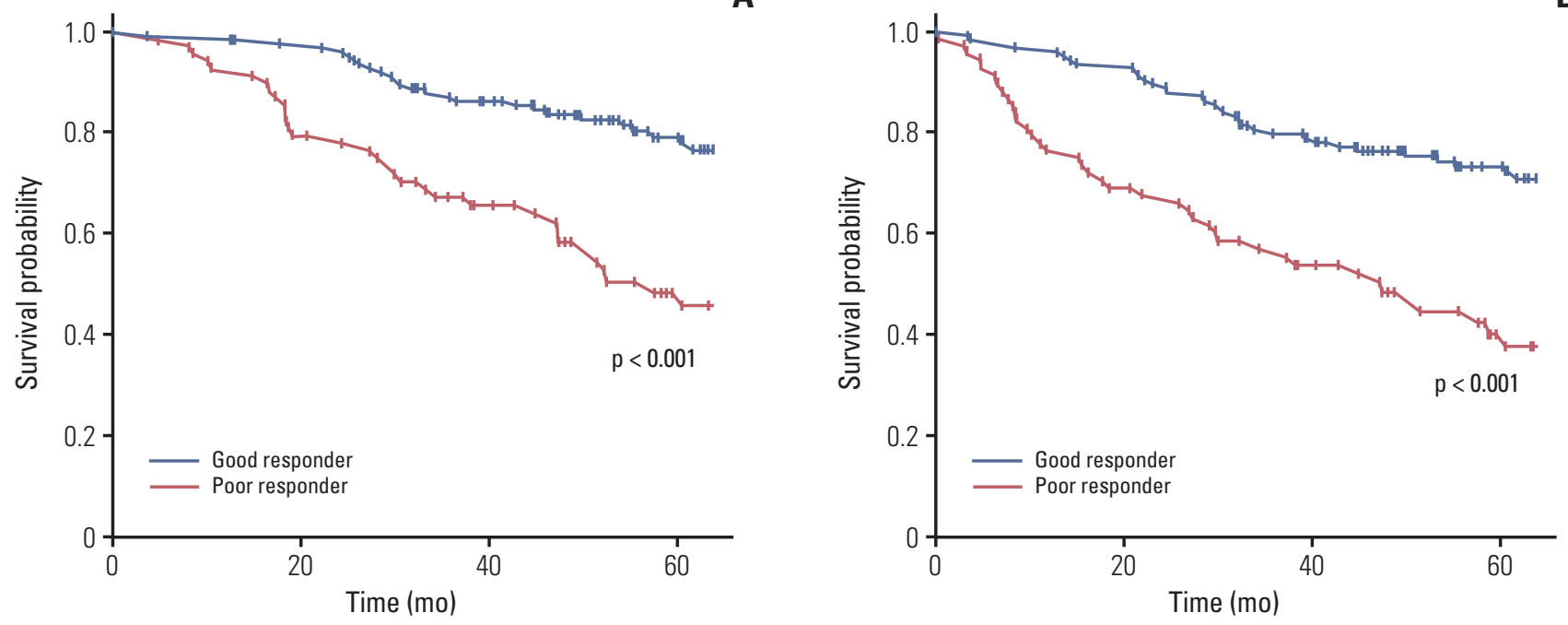

Fig. 1. Survival curve according to treatment response. Good responders, treatment response of grade 2 or 3 ; poor responders, grade 0 or 1. (A) Overall survival. (B) Locoregional recurrence-free survival.

\section{Results}

\section{Patient population}

In total, data of 197 patients were collected from the database of seven participating cancer centers. Four patients were excluded due to following reasons. Three patients had CRM over $2 \mathrm{~mm}$, and one patient had preoperative treatment stage cT2N0M0. Thus, 193 patients were analyzed (Table 1).

\section{Treatments}

Preoperative radiotherapy dose ranged from 44 to 54 Gy (median, 50.4 Gy) with 1.8-2.0 Gy per fraction. All patients underwent concurrent chemotherapy with radiation, consisting of a 5-fluorouracil-based regimen $(n=137)$, capecitabinebased regimen $(n=51)$, and tegafur/uracil $(n=5)$. TME was performed 4-12 weeks (median, 7.1 weeks) after preoperative CRT. Sphincter preservation surgery and abdominoperineal resection were performed in $140(72.5 \%)$ and $53(27.5 \%)$ patients, respectively.

Postoperative treatment was chemotherapy alone (90.4\%), radiotherapy alone $(0.8 \%)$, CRT $(3.2 \%)$, and observation (5.6\%) for good responders, whereas chemotherapy alone (91.2\%), CRT $(1.5 \%)$, and observation $(7.4 \%)$ for poor responders. The distribution of postoperative treatment and postoperative chemotherapy regimen according to treatment response was not statistical significant $(\mathrm{p}=0.736$ and $\mathrm{p}=0.801$, respectively).

In patients with involved CRM $(\mathrm{n}=32)$, postoperative treat- ment was chemotherapy alone $(93.8 \%)$, and observation $(6.2 \%)$. In patients with close CRM $(n=161)$, postoperative treatment was chemotherapy alone $(90.1 \%)$, radiotherapy alone $(0.6 \%)$, CRT $(3.1 \%)$, and observation $(6.2 \%)$. The distributions of postoperative treatment and postoperative chemotherapy were also not significantly different according to CRM status ( $\mathrm{p}=0.745$ and $\mathrm{p}=0.904$, respectively).

\section{Pathologic findings}

The ypT classification was ypTis in one patient $(0.5 \%)$, ypT1 in two (1.0\%), ypT2 in $23(11.9 \%)$, ypT3 in $150(77.8 \%)$, and ypT4 in $17(8.8 \%)$. The ypN classification were ypN0 in 92 patients (47.7\%), ypN1 in 66 (34.2\%), and ypN2 in $35(18.1 \%)$. CRM was involved $(0 \mathrm{~mm})$ in 32 patients $(16.6 \%), 0.1-1.0 \mathrm{~mm}$ in $87(45.1 \%)$, and 1.1-2.0 $\mathrm{mm}$ in $74(38.3 \%)$. $\mathrm{T}$ downstaging was found in 33 patients $(17.1 \%)$. Treatment response was grade 0 in eight patients $(4.1 \%)$, grade 1 in $60(31.1 \%)$, grade 2 in $113(58.5 \%)$, and grade 3 in $12(6.2 \%)$. Thus, the number of good responders and poor responders was 125 and 68, respectively.

The preoperative and treatment factors were not related to treatment response (Table 1). Distribution of pretreatment factors including age, sex, ECOG, $\mathrm{cT}, \mathrm{cN}$, distance from anal verge, and pretreatment CEA, interval from CRT to surgery were not significantly different between two groups. However, advanced ypT and ypN were more frequent among the poor responders. Involved CRM, lymphatic invasion, and vascular invasion were significantly related to poor response.

CRM involvement was not related to distance from anal 
Table 2. Univariate analysis of factors affecting clinical outcome

\begin{tabular}{|c|c|c|c|c|c|c|c|c|c|}
\hline & No. & $\begin{array}{c}\text { 5-Year } \\
\text { OS }^{a}\end{array}$ & p-value ${ }^{\text {b) }}$ & $\begin{array}{l}\text { 5-Year } \\
\text { DFS }^{\text {a) }}\end{array}$ & p-value ${ }^{\text {b) }}$ & $\begin{array}{l}\text { 5-Year } \\
\text { LRFS }^{\text {a) }}\end{array}$ & p-value ${ }^{\text {b) }}$ & $\begin{array}{l}\text { 5-Year } \\
\text { DMFS }^{a}\end{array}$ & p-value ${ }^{\text {b) }}$ \\
\hline \multicolumn{10}{|l|}{ Age (yr) } \\
\hline$<60$ & 102 & 69.5 & 0.476 & 45.3 & 0.174 & 60.6 & 0.960 & 49.8 & 0.238 \\
\hline$\geq 60$ & 91 & 67.2 & & 56.7 & & 62.9 & & 58.3 & \\
\hline \multicolumn{10}{|l|}{ Sex } \\
\hline Male & 127 & 61.5 & 0.001 & 45.3 & 0.027 & 54.4 & 0.002 & 48.5 & 0.014 \\
\hline Female & 66 & 80.7 & & 59.8 & & 74.9 & & 63.7 & \\
\hline \multicolumn{10}{|l|}{ ECOG score } \\
\hline 0 & 91 & 72.9 & 0.003 & 55.2 & 0.083 & 67.4 & 0.008 & 57.6 & 0.101 \\
\hline 1 & 98 & 65.8 & & 48.1 & & 57.4 & & 52.3 & \\
\hline $2-3$ & 4 & 25.0 & & 0.0 & & 25.0 & & 0.0 & \\
\hline \multicolumn{10}{|c|}{ Clinical $\mathrm{T}$ classification } \\
\hline $\mathrm{T} 2 / 3$ & 170 & 69.4 & 0.219 & 51.1 & 0.434 & 62.8 & 0.220 & 54.3 & 0.405 \\
\hline $\mathrm{T} 4$ & 23 & 64.7 & & 47.8 & & 56.2 & & 52.2 & \\
\hline \multicolumn{10}{|c|}{ Clinical N classification } \\
\hline $\mathrm{N}(-)$ & 36 & 77.0 & 0.204 & 72.0 & 0.007 & 71.2 & 0.098 & 71.5 & 0.019 \\
\hline $\mathrm{N}(+)$ & 157 & 66.4 & & 45.3 & & 58.5 & & 49.5 & \\
\hline \multicolumn{10}{|c|}{ Distance from anal verge $(\mathrm{cm})$} \\
\hline$\leq 2$ & 50 & 73.5 & 0.281 & 65.0 & 0.046 & 68.4 & 0.251 & 67.0 & 0.074 \\
\hline$>2$ and $\leq 5$ & 89 & 68.2 & & 45.8 & & 59.9 & & 48.4 & \\
\hline$>5$ & 54 & 63.7 & & 44.4 & & 58.3 & & 49.7 & \\
\hline \multicolumn{10}{|c|}{ Pretreatment CEA (ng/mL) } \\
\hline$\leq 5$ & 104 & 71.9 & 0.228 & 55.4 & 0.147 & 66.8 & 0.097 & 58.0 & 0.232 \\
\hline$>5$ & 86 & 64.6 & & 44.3 & & 55.7 & & 48.5 & \\
\hline \multicolumn{10}{|l|}{ Chemotherapy } \\
\hline 5-Fluorouracil & 137 & 64.6 & 0.517 & 45.6 & 0.285 & 56.3 & 0.263 & 50.1 & 0.336 \\
\hline $\mathrm{X}, \mathrm{X}+$ irinotecan $\pm \mathrm{E}$ & 51 & 77.5 & & 62.4 & & 69.6 & & 63.8 & \\
\hline Tegafur/Uracil & 5 & 80.0 & & 60.0 & & 80.0 & & 60.0 & \\
\hline \multicolumn{10}{|l|}{ Type of surgery } \\
\hline LAR & 140 & 70.9 & 0.375 & 52.3 & 0.501 & 63.9 & 0.289 & 56.7 & 0.234 \\
\hline APR & 53 & 62.1 & & 46.0 & & 55.8 & & 46.0 & \\
\hline \multicolumn{10}{|l|}{ Response } \\
\hline $0 / 1$ & 68 & 48.4 & $<0.001$ & 30.8 & $<0.001$ & 40.3 & $<0.001$ & 34.1 & $<0.001$ \\
\hline $2 / 3$ & 125 & 79.1 & & 61.1 & & 73.2 & & 63.9 & \\
\hline \multicolumn{10}{|l|}{ ypT classification } \\
\hline Tis/T1/T2 & 26 & 100.0 & $<0.001$ & 76.9 & $<0.001$ & 88.5 & $<0.001$ & 80.8 & $<0.001$ \\
\hline $\mathrm{T} 3$ & 150 & 66.0 & & 49.1 & & 61.0 & & 52.0 & \\
\hline $\mathrm{T} 4$ & 17 & 45.4 & & 23.5 & & 29.4 & & 29.4 & \\
\hline \multicolumn{10}{|l|}{ ypN classification } \\
\hline No & 92 & 77.1 & $<0.001$ & 65.2 & $<0.001$ & 70.9 & $<0.001$ & 67.3 & $<0.001$ \\
\hline N1 & 66 & 72.6 & & 47.2 & & 65.5 & & 51.1 & \\
\hline N2 & 35 & 38.1 & & 17.1 & & 30.6 & & 22.2 & \\
\hline \multicolumn{10}{|l|}{ Downstage } \\
\hline Yes & 75 & 77.1 & 0.026 & 63.9 & 0.003 & 69.5 & 0.035 & 66.4 & 0.004 \\
\hline No & 118 & 62.8 & & 42.0 & & 56.6 & & 45.6 & \\
\hline \multicolumn{10}{|l|}{ CRM distance $(\mathrm{mm})$} \\
\hline 0 & 32 & 29.4 & $<0.001$ & 21.9 & $<0.001$ & 30.1 & $<0.001$ & 24.6 & $<0.001$ \\
\hline $0.1-1.0$ & 87 & 73.0 & & 58.4 & & 65.8 & & 62.3 & \\
\hline $1.1-2.0$ & 74 & 72.6 & & 54.1 & & 68.7 & & 56.3 & \\
\hline
\end{tabular}

(Continued to the next page) 
Table 2. Continued

\begin{tabular}{|c|c|c|c|c|c|c|c|c|c|}
\hline & No. & $\begin{array}{l}\text { 5-Year } \\
\text { OS }^{a}\end{array}$ & p-value ${ }^{\text {b) }}$ & $\begin{array}{l}\text { 5-Year } \\
\text { DFS }^{\text {a) }}\end{array}$ & p-value ${ }^{b)}$ & $\begin{array}{l}\text { 5-Year } \\
\text { LRFS }^{\text {a) }}\end{array}$ & p-value ${ }^{\text {b) }}$ & $\begin{array}{l}\text { 5-Year } \\
\text { DMFS }^{a}\end{array}$ & p-value ${ }^{\text {b) }}$ \\
\hline \multicolumn{10}{|c|}{ Lymphatic invasion } \\
\hline Yes & 56 & 49.8 & $<0.001$ & 29.1 & $<0.001$ & 43.4 & $<0.001$ & 30.1 & $<0.001$ \\
\hline No & 136 & 76.0 & & 59.0 & & 69.0 & & 63.1 & \\
\hline \multicolumn{10}{|c|}{ Vascular invasion } \\
\hline Yes & 49 & 49.7 & 0.001 & 33.7 & 0.001 & 43.5 & 0.001 & 35.8 & 0.002 \\
\hline No & 140 & 75.0 & & 55.8 & & 72.6 & & 59.5 & \\
\hline \multicolumn{10}{|c|}{ Perinerual invasion } \\
\hline Yes & 76 & 48.7 & $<0.001$ & 25.1 & $<0.001$ & 40.6 & $<0.001$ & 27.5 & $<0.001$ \\
\hline No & 113 & 81.4 & & 66.2 & & 75.3 & & 70.0 & \\
\hline \multicolumn{10}{|c|}{$\begin{array}{l}\text { Adjuvant chemotherapy/ } \\
\text { Chemoradiotherapy }\end{array}$} \\
\hline Yes & 180 & 69.3 & 0.273 & 50.2 & 0.804 & 62.1 & 0.573 & 53.6 & 0.977 \\
\hline No & 13 & 57.7 & & 57.7 & & 57.7 & & 57.7 & \\
\hline
\end{tabular}

OS, overall survival; DFS, disease-free survival; LRFS, locoregional-free survival; DMFS, distant metastasis-free survival; ECOG, Eastern Cooperative Oncology Group; CEA, carcinoembryonic antigen; X, capecitabine; E, cetuximab; LAR, low anterior resection; APR, abdominoperineal resection; CRM, circumferential resection margin. ${ }^{\text {a) }}$ Values are percentages of patients, b) Log-rank test.

Table 3. Multivariate analysis of factors affecting clinical outcome

\begin{tabular}{|c|c|c|c|c|}
\hline & \multicolumn{4}{|c|}{ HR $(95 \% \mathrm{CI})$} \\
\hline & Os & DFS & LRFS & DMFS \\
\hline Sex & $2.27(1.17-4.42)$ & NS & $1.81(1.02-3.20)$ & NS \\
\hline Performance status & $2.23(1.39-3.56)$ & - & NS & - \\
\hline Distance from AV & - & NS & - & - \\
\hline cN classification & - & $1.92(1.01-3.67)$ & - & NS \\
\hline ypT classification & NS & NS & NS & NS \\
\hline ypN classification & NS & NS & NS & $1.65(1.02-2.66)$ \\
\hline Treatment response & $1.87(1.09-3.19)$ & NS & $1.99(1.24-3.19)$ & NS \\
\hline Downstaging & NS & NS & NS & NS \\
\hline CRM involvement & $3.35(1.66-6.76)$ & $2.89(1.71-4.90)$ & $2.66(1.44-4.92)$ & $2.53(1.46-4.38)$ \\
\hline Lymphatic invasion & NS & NS & NS & $1.71(1.07-2.75)$ \\
\hline Venous invasion & NS & NS & NS & NS \\
\hline Perineural invasion & $2.45(1.42-4.22)$ & $2.50(1.60-3.93)$ & $2.77(1.72-4.46)$ & $2.27(1.46-4.38)$ \\
\hline
\end{tabular}

HR, hazard ratio; CI, confidence interval; OS, overall survival; DFS, disease-free survival; LRFS, locoregional-free survival; DMFS, distant metastasis-free survival; NS, not significant; -, exclusion from Cox proportional hazard model during backward stepwise selection procedure; AV, anal verge; CRM, circumferential resection margin.

verge and type of surgery ( $p=0.199$ and $p=0.817)$. However, the advanced cT was significantly related to the involvement of CRM ( $\mathrm{p}=0.006)$. In patients with involved CRM, cT stage was cT2-3 in 23 patients $(71.9 \%)$ and cT4 in nine $(28.1 \%)$, while cT2-3 and cT4 are 147 patients $(91.3 \%)$ and $14(8.7 \%)$ in patients with non-involved CRM.

\section{Survival and prognostic factors}

Median follow-up duration was 52.0 months (range, 4.0 to 113.0 months). Five-year OS, DFS, LRFS, and DMFS were $68.4 \%, 50.6 \%, 61.7 \%$, and $53.8 \%$, respectively.

The primary objective of the study, demonstrating a signif- 
Table 4. Subgroup analysis according to treatment response and circumferential margin status

\begin{tabular}{|c|c|c|c|c|c|c|c|c|c|c|}
\hline CRM & $\begin{array}{l}\text { Treatment } \\
\text { response }\end{array}$ & No. & $\begin{array}{c}\text { 5-Year } \\
\text { OS }\end{array}$ & p-value ${ }^{a)}$ & $\begin{array}{c}\text { 5-Year } \\
\text { DFS }\end{array}$ & p-value ${ }^{a)}$ & $\begin{array}{l}\text { 5-Year } \\
\text { LRFS }\end{array}$ & p-value & $\begin{array}{l}\text { 5-Year } \\
\text { DMFS }\end{array}$ & p-value ${ }^{a}$ \\
\hline Close & Good & 117 & 81.2 & $<0.001$ & 62.7 & $<0.001$ & 74.9 & $<0.001$ & 65.8 & $<0.001$ \\
\hline Close & Poor & 44 & 57.0 & & 38.6 & & 49.7 & & 41.5 & \\
\hline Involved & Good & 8 & 50.0 & & 37.5 & & 50.0 & & 37.5 & \\
\hline Involved & Poor & 24 & 32.4 & & 16.7 & & 23.8 & & 19.5 & \\
\hline
\end{tabular}

CRM, circumferential resection margin; OS, overall survival; DFS, disease-free survival; LRFS, locoregional-free survival; DMFS, distant metastasis-free survival. a) Log-rank test.

A

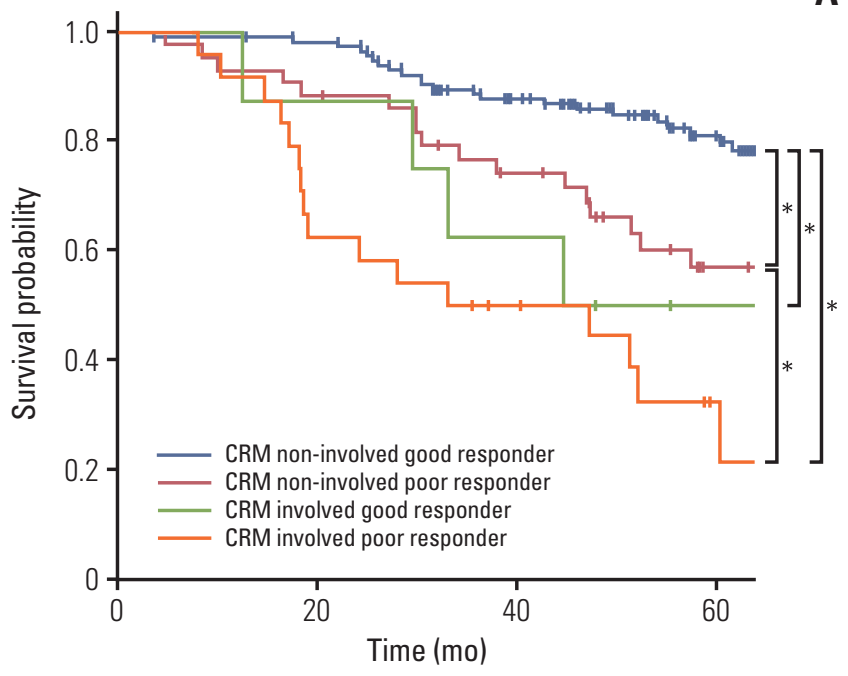

Fig. 2. Subgroup analysis according to circumferential resection margin (CRM) status and treatment response. Good responders, treatment response grade 2 and 3; poor responders, treatment response grade 0 and $1 .{ }^{*} \mathrm{p}<0.05$ (Kaplan-Meier analysis). (A) Overall survival. (B) Locoregional recurrence-free survival.

icant difference in OS between good and poor responders was met ( $\mathrm{p}<0.001 ; 5$-year OS in good and poor responders, 79.1\% and $48.4 \%$, respectively). For secondary end-points, good responders also had significantly superior prognosis compared to poor responders in all studied end-points (Fig. 1). Univariate analysis for other prognostic factors revealed that gender, ypT, ypN, downstaging, T-downstaging, CRM distance, lymphatic invasion, vascular invasion, and perineural invasion were significant prognostic factors for OS, DFS, LRFS, and DMFS. In addition, ECOG class was a significant prognostic factor for OS and LRFS. Clinical N classification was significantly related to DFS and DMFS. Distance from anal verge was a significant prognosticator for DFS (Table 2).

Although there was uneven distribution of prognostic factors for ypT, ypN, CRM involvement, downstaging, lymphatic

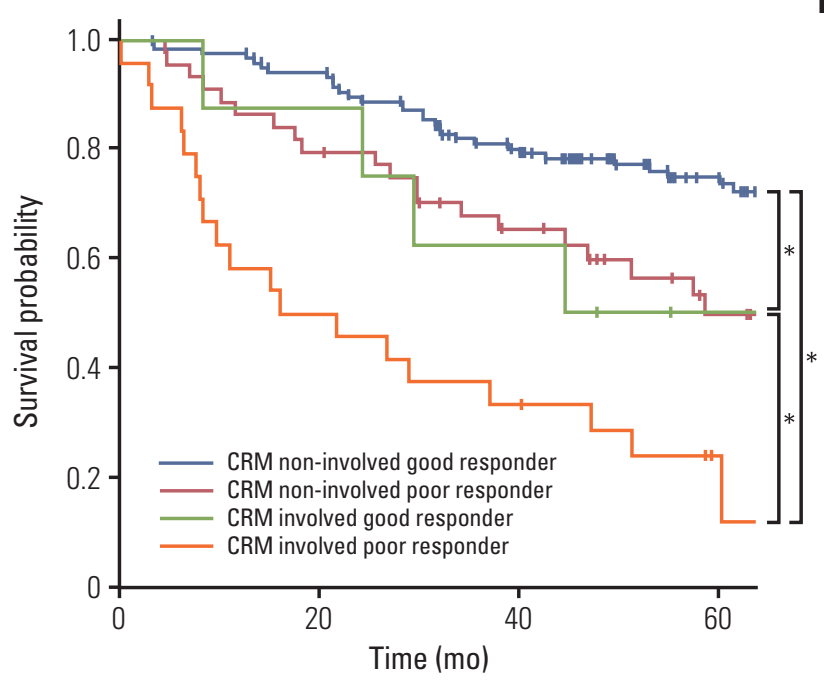

invasion, vascular invasion, and perineural invasion, multivariate analysis showed that treatment response was an independently significant prognostic factor for OS and LRFS (Table 3). In addition, CRM involvement and perineural invasion were independent prognostic factors for all studied endpoints. Gender and ECOG score were independent significant prognostic factors for OS. In addition, sex was also independently significant for LRFS, and ypN was an independently significant prognostic factor for DMFS.

\section{Subgroup analysis according to treatment response and CRM status}

To further evaluate the relationship between treatment response and CRM status, subgroup analysis according to 
A
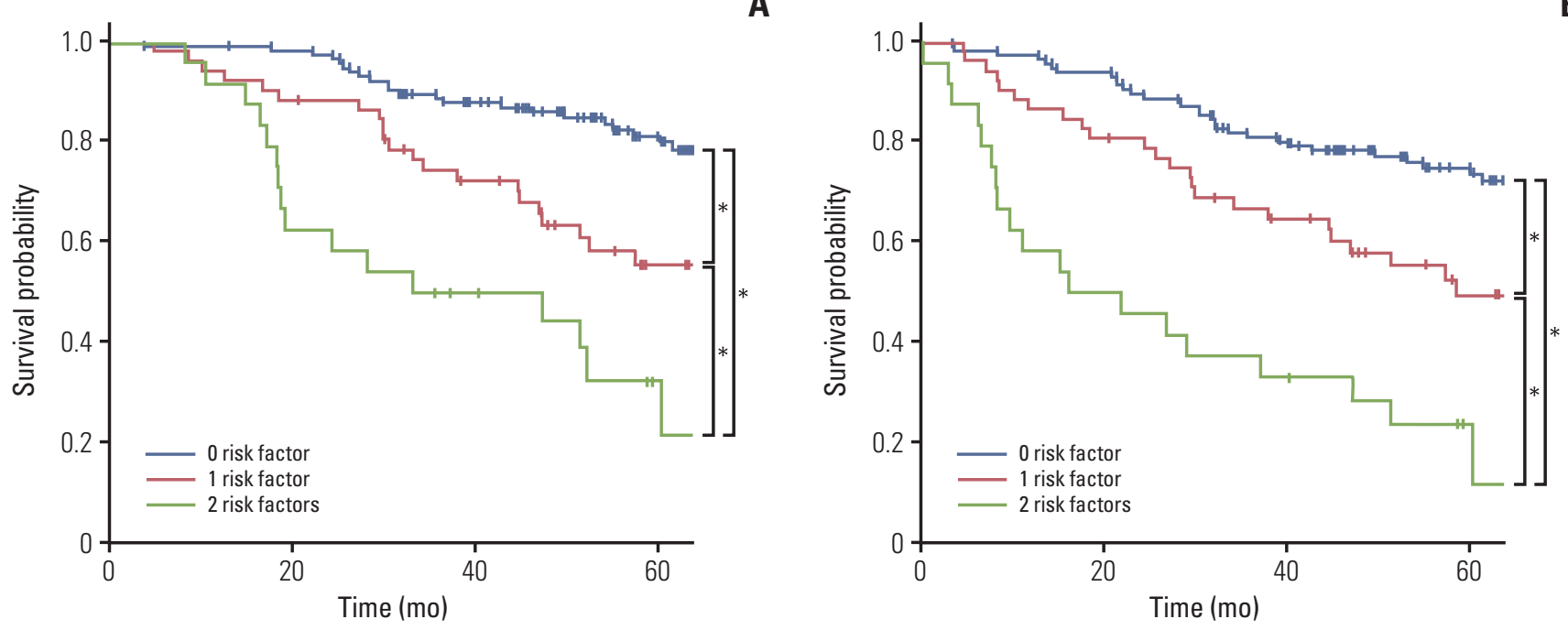

Fig. 3. Subgroup analysis according to risk stratification by poor treatment response and involved margin risk factors include the involvement of circumferential resection margin and treatment response. (A) Overall survival. (B) Locoregional recurrence-free survival. ${ }^{*} \mathrm{p}<0.05$ (Kaplan-Meier analysis).

given two factors was performed (Table 4). Clinical outcomes of good responders with close CRM, which constituted over $60 \%$ in the current analysis, were far superior to other subgroups in all studied endpoints $(\mathrm{p}<0.005)$. Good responders with involved CRM showed outcomes similar to that of poor responders with close CRM in all studied endpoints, whereas those of poor responders with involved CRM were inferior significantly in LRFS ( $p<0.001$ to non-involved CRM, and 0.048 to good responders with non-involved CRM) and OS ( $\mathrm{p}<0.001$ to non-involved CRM) (Fig. 2). Good responders with involved CRM had a 5-year OS of 50\%, compared to $32 \%$ for poor responders with involved CRM; however, the difference was not significant $(p=0.112)$. When patients were re-grouped based on the risk of either poor response or involved margin, significant difference between all subgroups was seen for all studied end-points ( $p<0.001)$ (Fig. 3).

\section{Discussion}

The aim of the current study was to validate the hypothesis that the effect and definition of CRM could be different according to treatment response [7]. To analyze clinical characteristics of patients with positive CRM, the current study was designed to accrue homogenous cohort with positive CRM defined as $C R M \leq 2 \mathrm{~mm}$ after preoperative long-course
CRT and TME. Although there is a controversy in defining positive CRM, CRM > $2 \mathrm{~mm}$ has been accepted as negative CRM in the previous studies or guidelines $[3,6]$. To overcome limitation of small sample size of the pilot study from single institution [7], multicenter study was initiated through KROG. From seven participating referral centers, 197 patients with relatively homogenous characteristics of positive CRM, preoperative long-course CRT, and identical guideline for surgical pathology review were accrued.

The result showed the importance of treatment response in understanding the impact of CRM for the patients after preoperative CRT. There have been studies looking into the prognostic impact of treatment response based on tumor regression in rectal cancer [10-12,15]. However, prognostic value in all patients had been limited to local control, and not survival [11,12], or was not comparable to the value of yp-classification in multivariate analysis $[10,15]$. Unlike the previous studies, where all patients were included for analysis, current study focused on the patients with positive CRM. Results showed that the treatment response was an independent and significant factor in the prognosis through the multivariate analysis. Interestingly, yp-classifications, a powerful prognosticator in the general patients, lost the statistical significance for OS and LRFS in the multivariate analysis. Influence of ypN on DMFS was the only effect that yp-classification had on prognosis in current study. Patient and treatment characteristics were not significantly different between good and poor responders as shown in Table 1, 
except pathologic findings such as yp-classification. Although the various well acknowledged pathologic factors were found to carry prognostic significance in univariate analysis, treatment response remained as the pathologic prognostic indicator after multivariate analysis. Perineural invasion was another exception. As positive CRM refers to a high risk of residual disease, the aggressiveness or treatment resistance of the possible residual tumor may be more important than other factors, such as the level of tumor invasion or downstaging. Therefore, it could be postulated that treatment response plays a significant and independent role in the outcome of patients with positive CRM.

CRM involvement, defined as clearance of $0 \mathrm{~mm}$, was also related to distinctively deteriorated outcomes, compared to close CRM, either defined as $\leq 1$ or $2 \mathrm{~mm}$ in the current study. Although patients with limited clearance but without involvement, otherwise termed close CRM, had prognosis far worse than those with patients with sufficient clearance, patients with involved CRM had inferior outcomes to those with close, but non-involved CRM [3]. Despite this innate difference, these patients were seen as a single group. Thus, without doubt, involved CRM should be classified as positive CRM, irrespective of the other pathologic factors.

The relevant major issue that followed was optimal cut-off point for positive CRM in various settings $[1,3,5,6]$. Currently employed definitions of positive CRM uses fixed clearance, including involvement, irrespective of individual tumor behavior of residual microscopic disease. The issue on the definition of positive CRM is closely related with the postoperative approach to this subgroup of patients. Various treatment approaches, either postoperatively or preoperatively have been employed to overcome the negative impact of positive CRM. In the previous reports, intensification of postoperative treatment with additional radiotherapy $[16,17]$ failed to obtain substantial benefit after long-term follow-up. Even though intraoperative radiotherapy is recommended as an option to compensate for positive CRM, the evidence to support this practice is somewhat limited in both treatment efficacy and survival benefit [18]. Likewise, except for one study, more recent prospective series have not shown survival benefit with more intensified chemotherapy over standard fluoropyrimidine based chemotherapy [19-22]. One reason, among many, may be non-individualized approach. Some groups might be under-treated whereas the others might be over-treated, which mixes the benefit or loss of postoperative treatment.

In current study, the treatment response and involved CRM were the independent and significant determinant in the patients with the limited clearance from tumor. Reported 5 -year overall survival for patients with positive CRM is around $60 \%$ with prevalence of $30 \%$ among patients undergoing preoperative CRT. However, as shown in the current study, even among patients with positive CRM, survival of approximately $80 \%$ for good responders with close CRM is more or less similar to those of patients with wide CRM in various series $[3,4,7,8]$. Thus, suitable treatment strategy may be similar to that for patients with wide CRM, and treatment intensification based on positive CRM could be over-treatment for this subgroup. Of note is that this subgroup constituted nearly $60 \%$ of patients with positive CRM in the current analysis. Thus, for patients with non-involved CRM, good responders might be classified as having negative CRM, whereas poor responders with clearance $\leq 2 \mathrm{~mm}$ should be defined as having positive CRM.

Furthermore, after excluding good responders with close CRM from the current definition of patients with positive CRM, remaining patients could be further grouped into two using CRM involvement and treatment response. Good responder with involved CRM or poor responder with close CRM are patients with one risk factor and share a 5-year OS in the range of $50 \%$. Those with two risks, meaning poor responder with involved CRM, are distinctive group with worst prognosis with 5-year OS in the range of 30\%, quite similar to those with R2 resection, though they are considered to have undergone R1 resection. Thus, postoperative treatment could be also intensified and individualized according to the treatment response and CRM involvement in these patients.

Although current study is hypothesis-driven, pre-designed validation study, it is not free from its innate limitations. First, employed chemotherapy regimens were heterogeneous, although difference in chemotherapy was not distinctly associated with survival nor was its distribution different between the responding groups. Second, adjuvant treatment including chemotherapy was also heterogeneous. However, distribution of subgroup was well balanced for adjuvant treatment nor was adjuvant treatment significant factor for survival. Third, though present study suggests individualized definition for positive CRM and postoperative approach based on treatment response, the optimal individualized strategy consisting of intensified or de-intensified treatment according to treatment response could not be postulated, due to lack of comparative group with different adjuvant strategies. Fourth, though the definition of CRM was sought as main goal, size of subgroup for the analysis was not incorporated in initial study design. Fifth, the outcome of good responders without involved CRM was compared to patients with wide CRM in the selected cohort and data driven from literature review. Six, the size of the subgroup, especially, good responder with involved CRM was too small to reach an indisputable conclusion. Thus, findings from current study may warrant further validation at least with larger cohort. Seventh, this was not a prospective randomized trial. Thus, not free from inherent bias. Finally, 
although detailed surgical factors including surgical technique and intraoperative findings may be related to the CRM status, such findings were not incorporated in current analysis due to the innate limitation of initial study design.

In summary, the impact of positive CRM was different for treatment response to preoperative CRT. In subgroup analysis segregated by response and CRM involvement, good responders with close CRM could be a distinct subgroup with significantly better survival similar to that of patients with wide CRM, while poor responders with involved CRM could be another subgroup with the worst prognosis. Definition and treatment approach for positive CRM might be further adjusted according to treatment response and CRM involvement.

\section{Conflicts of Interest}

Conflict of interest relevant to this article was not reported.

\section{Acknowledgments}

Authors would like to thank Prof. Hong Seok Jang of Department of Radiation Oncology, Seoul St. Mary's Hospital, College of Medicine, The Catholic University of Korea and Prof. Jin Hee Kim of Department of Radiation Oncology, Dongsan Medical Center, Keimyung University School of Medicine for patient accrual.

This research was partly supported by Natinal R\&D Program through the Dong-nam Institute of Radiological \& Medical Sciences (DIRAMS) funded by the Ministry of Science, ICT \& Future Planning (DIRAMS grant number 50590-2017).

\section{Author Details}

Departments of ${ }^{1}$ Radiation Oncology, ${ }^{2}$ Surgery, and ${ }^{3}$ Internal Medicine, Seoul National University College of Medicine, Seoul, ${ }^{4}$ Center for Colorectal Cancer, Research Institute and Hospital, National Cancer Center, Goyang, 5 Department of Radiation Oncology, St. Vincent's Hospital, College of Medicine, The Catholic University of Korea, Suwon, ${ }^{6}$ Department of Radiation Oncology, Samsung Medical Center, Sung-kyunkwan University School of Medicine, Seoul, Departments of ${ }^{7}$ Surgery and ${ }^{8}$ Radiation Oncology, Seoul National University Bundang Hospital, Seongnam, Korea

\section{References}

1. Adam IJ, Mohamdee MO, Martin IG, Scott N, Finan PJ, Johnston D, et al. Role of circumferential margin involvement in the local recurrence of rectal cancer. Lancet. 1994;344:707-11.

2. Quirke P, Durdey P, Dixon MF, Williams NS. Local recurrence of rectal adenocarcinoma due to inadequate surgical resection: histopathological study of lateral tumour spread and surgical excision. Lancet. 1986;2:996-9.

3. Nagtegaal ID, Marijnen CA, Kranenbarg EK, van de Velde CJ, van Krieken JH; Pathology Review Committee, et al. Circumferential margin involvement is still an important predictor of local recurrence in rectal carcinoma: not one millimeter but two millimeters is the limit. Am J Surg Pathol. 2002;26:350-7.

4. Trakarnsanga A, Gonen M, Shia J, Goodman KA, Nash GM, Temple LK, et al. What is the significance of the circumferential margin in locally advanced rectal cancer after neoadjuvant chemoradiotherapy? Ann Surg Oncol. 2013;20:1179-84.

5. Wibe A, Rendedal PR, Svensson E, Norstein J, Eide TJ, Myrvold HE, et al. Prognostic significance of the circumferential resection margin following total mesorectal excision for rectal cancer. Br J Surg. 2002;89:327-34.

6. National Comprehensive Cancer Network. NCCN clincal practice guidelines in oncology: rectal cancer version 3.2014 [Internet]. Fort Washington, PA: National Comprehensive Cancer Network; 2014 [cited 2014 Feb 4]. Available from: http: // www.nccn.org/professionals/physician_gls/pdf/rectal.pdf.
7. Lee JH, Chie EK, Kim K, Jeong SY, Park KJ, Park JG, et al. The influence of the treatment response on the impact of resection margin status after preoperative chemoradiotherapy in locally advanced rectal cancer. BMC Cancer. 2013;13:576.

8. Bernstein TE, Endreseth BH, Romundstad P, Wibe A; Norwegian Colorectal Cancer Group. Circumferential resection margin as a prognostic factor in rectal cancer. Br J Surg. 2009;96: 1348-57.

9. Glynne-Jones R, Mawdsley S, Novell JR. The clinical significance of the circumferential resection margin following preoperative pelvic chemo-radiotherapy in rectal cancer: why we need a common language. Colorectal Dis. 2006;8:800-7.

10. Rodel C, Martus P, Papadoupolos T, Fuzesi L, Klimpfinger M, Fietkau R, et al. Prognostic significance of tumor regression after preoperative chemoradiotherapy for rectal cancer. J Clin Oncol. 2005;23:8688-96.

11. Ruo L, Tickoo S, Klimstra DS, Minsky BD, Saltz L, Mazumdar $\mathrm{M}$, et al. Long-term prognostic significance of extent of rectal cancer response to preoperative radiation and chemotherapy. Ann Surg. 2002;236:75-81.

12. Bouzourene H, Bosman FT, Seelentag W, Matter M, Coucke $\mathrm{P}$. Importance of tumor regression assessment in predicting the outcome in patients with locally advanced rectal carcinoma who are treated with preoperative radiotherapy. Cancer. 2002;94:1121-30.

13. Edge SB, Byrd DR, Compton CC, Fritz AG, Greeene FL, Trotti 
A. AJCC cancer staging manual. 7th ed. New York: SpringerVerlag; 2010.

14. Dworak O, Keilholz L, Hoffmann A. Pathological features of rectal cancer after preoperative radiochemotherapy. Int J Colorectal Dis. 1997;12:19-23.

15. Kim TH, Chang HJ, Kim DY, Jung KH, Hong YS, Kim SY, et al. Pathologic nodal classification is the most discriminating prognostic factor for disease-free survival in rectal cancer patients treated with preoperative chemoradiotherapy and curative resection. Int J Radiat Oncol Biol Phys. 2010;77: 1158-65.

16. Sebag-Montefiore D, Stephens RJ, Steele R, Monson J, Grieve $\mathrm{R}$, Khanna S, et al. Preoperative radiotherapy versus selective postoperative chemoradiotherapy in patients with rectal cancer (MRC CR07 and NCIC-CTG C016): a multicentre, randomised trial. Lancet. 2009;373:811-20.

17. Marijnen CA, Nagtegaal ID, Kapiteijn E, Kranenbarg EK, Noordijk EM, van Krieken JH, et al. Radiotherapy does not compensate for positive resection margins in rectal cancer patients: report of a multicenter randomized trial. Int J Radiat Oncol Biol Phys. 2003;55:1311-20.

18. Alberda WJ, Verhoef C, Nuyttens JJ, van Meerten E, Rothbarth $\mathrm{J}$, de Wilt $\mathrm{JH}$, et al. Intraoperative radiation therapy reduces local recurrence rates in patients with microscopically involved circumferential resection margins after resection of locally advanced rectal cancer. Int J Radiat Oncol Biol Phys. 2014;88:1032-40.

19. Gerard JP, Azria D, Gourgou-Bourgade S, Martel-Laffay I, Hennequin C, Etienne PL, et al. Comparison of two neoadjuvant chemoradiotherapy regimens for locally advanced rectal cancer: results of the phase III trial ACCORD 12/0405-Prodige 2. J Clin Oncol. 2010;28:1638-44.

20. Rodel C, Liersch T, Becker H, Fietkau R, Hohenberger W, Hothorn T, et al. Preoperative chemoradiotherapy and postoperative chemotherapy with fluorouracil and oxaliplatin versus fluorouracil alone in locally advanced rectal cancer: initial results of the German CAO/ARO/AIO-04 randomised phase 3 trial. Lancet Oncol. 2012;13:679-87.

21. Aschele C, Cionini L, Lonardi S, Pinto C, Cordio S, Rosati G, et al. Primary tumor response to preoperative chemoradiation with or without oxaliplatin in locally advanced rectal cancer: pathologic results of the STAR-01 randomized phase III trial. J Clin Oncol. 2011;29:2773-80.

22. O'Connell MJ, Colangelo LH, Beart RW, Petrelli NJ, Allegra CJ, Sharif S, et al. Capecitabine and oxaliplatin in the preoperative multimodality treatment of rectal cancer: surgical end points from National Surgical Adjuvant Breast and Bowel Project trial R-04. J Clin Oncol. 2014;32:1927-34. 